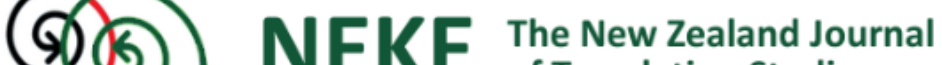 of Translation Studies
}

\section{When We Dead Awaken -What About the Living?}

Ibsen's masterpiece performed in English translation by the innovative theatre company Midsummer Night Players working with local and international talent.

A great deal has been written about translating for performance in general and for the theatre in particular, but nothing compares to the actual experience of it.

When We Dead Awaken, the final work of the Norwegian playwright, Henrik Ibsen (1828-1906), and the translated version by William Archer has been used for this sensational performance. It is a Midsummer Night Players Production directed by Emanuel E. Garcia.

The play showcases a depth of emotions and an astonishing performance from a multicultural cast; Julia Seemann as Irene, Coltan Stuart as Arnold Rubek, Lana Percival as Maia Rubek, Patrick McTague as Ulfheim, Michaeljohn Butcher as The Inspector, Hayley Morris as the sister of Mercy.

The two lead characters, Arnold Rubek and Irene, put on a phenomenal performance being able to portray difficult and intensely written personas in their perfect and individual way. The complex relationship explored between these two characters allows the audience to understand something of a different yet tragic aspect of life.

The play starts at a coastal spa with Arnold and Maia where they lay the foundation of their relationship. At the same time, a mysterious figure is introduced to the audience. The figure slides in like an illusion and builds to a crescendo.

The juxtaposition between the two principal female characters, Irene and Maia, portrays extreme contrasts in human nature. The strength and determination that builds during the performance become palpable toward the end. Maia's independence grows, and Irene takes us on a roller-coaster ride.

The multicultural cast brought layers of character emotion, and disposition portrayed allowed the audience an avenue to view the play from a personal perspective, and even gain a unique glimpse into their very own lives.

Watching the play was a life-changing experience allowing this reviewer - and, no doubt, the audiences that filled Gryphon Theatre in the heart of Wellington during the weeklong run - to have a deeper understanding of the complexities in life.

Alexandra Shelly-Rose Matthee

Alexandra Shelly-Rose Matthee, originally from South Africa, is a student at Wellington Girls College. 
(96) NEKE

\section{Henrik Ihsen's \\ When We Dead A waken}

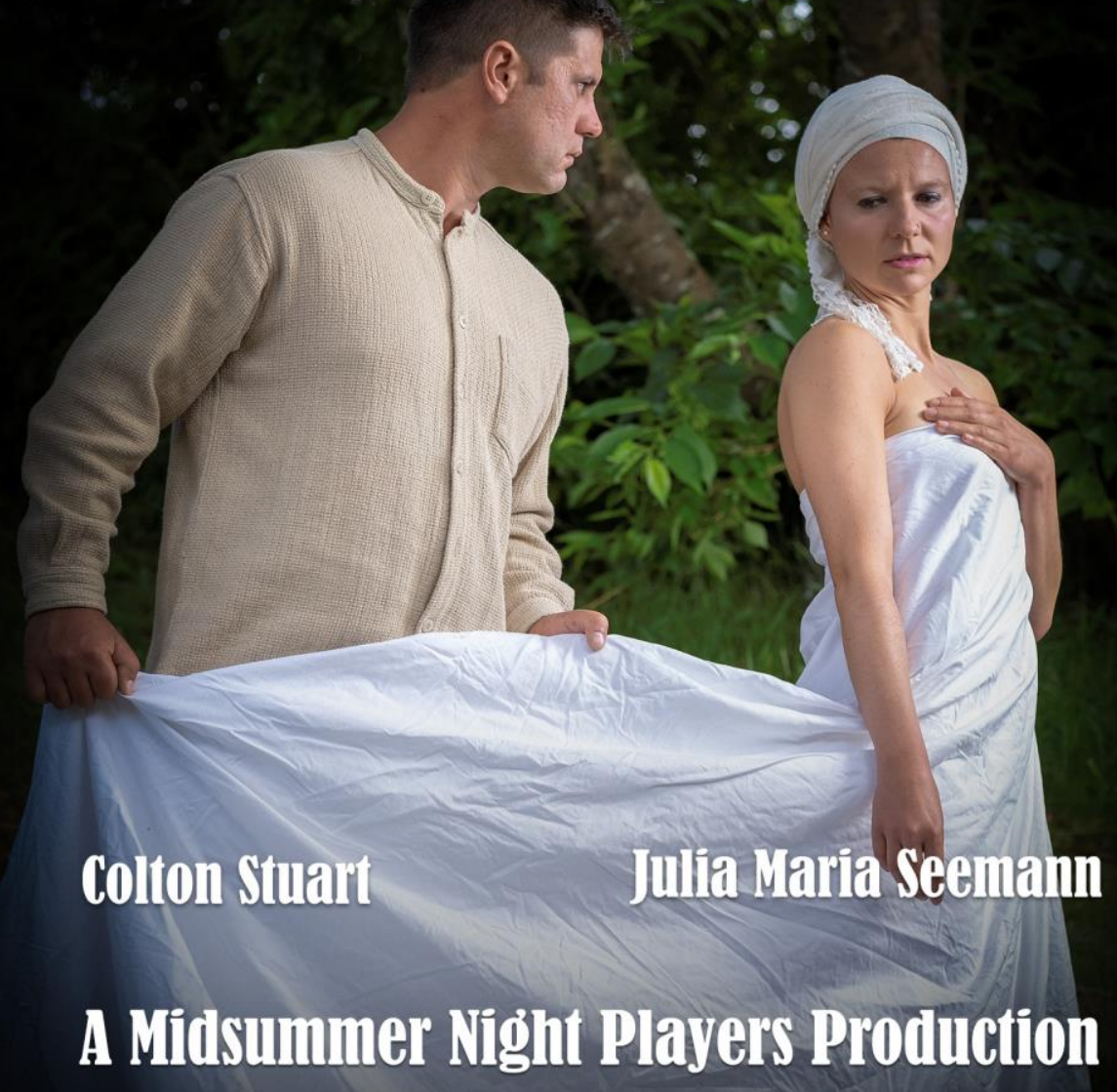

Directed by Emanucl E Garcia

The Gryphon Theatre

6-9 February 2019, 730 PM

Tickets: Eventfinda or Door Sales 